\title{
Study on Water Storage Change and Its Consideration in Water Balance in the Mountain Regions over Arid Northwest China
}

\author{
Min Xu \\ State Key Laboratory of Cryospheric Science, Cold and Arid Regions Environmental and Engineering Research Institute, \\ Chinese Academy of Sciences, Lanzhou 730000, China \\ Correspondence should be addressed to Min Xu; xumin@126.com
}

Received 22 August 2016; Revised 21 October 2016; Accepted 4 January 2017; Published 19 January 2017

Academic Editor: Luca Brocca

Copyright (C) 2017 Min Xu. This is an open access article distributed under the Creative Commons Attribution License, which permits unrestricted use, distribution, and reproduction in any medium, provided the original work is properly cited.

Changes in permafrost and glaciers influence water balance in mountain regions of arid northwest China. Terrestrial water storage change (TWSC) is an important factor in the water cycle. In this study, we used Gravity Recovery and Climate Experiment (GRACE) satellites data to retrieve the TWSC in Tien Shan and Qi Lian Mountains. Variation of seasonal TWSC was obvious. However, the seasonal and annual differences reflected the imbalance of water resource distribution in two mountains. The TWSC decreased in the Tien Shan Mountains but increased in the Qi Lian Mountains during 2003 to 2010. Permafrost and glaciers play an important role in the water cycle in arid mountain regions. Demands for water for agriculture need more groundwater extraction for irrigation and glacial melt feeding the rivers which leads to the state of loss of TWSC in Tien Shan Mountains. Increase and thickening of the active layer of permafrost could lead to more infiltration of surface water into the groundwater, which result in increasing water storage and changes in the regional water balance. According to water balance, precipitation and evaporation changed little in short time, and TWSC changed obviously, whereas runoff showed an increasing trend in the Tien Shan Mountains and a decreasing trend in the Qi Lian Mountains.

\section{Introduction}

Increasing vulnerability of the water resource systems threatens human well-being and the function of various ecoenvironmental systems in the arid Asian zone [1]. As precipitation predominantly occurs and glaciers (often called the "solid reservoir") are distributed in mountain regions, water resources are mainly provided by mountainous areas in the arid region of northwest China [2]

Tien Shan Mountains and Qi Lian Mountains are two regions of headwaters in arid northwest China. As an important landform, Tien Shan Mountains are regarded as water tower for supplies of agricultural and human population in the Chinese province of Xinjiang. The volume of the glaciers is about $1011 \mathrm{~km}^{3}$ in the Tien Shan Mountains, and runoff of the rivers originating from Tien Shan Mountains accounts for $50 \%$ of the total runoff at least in Xinjiang $[3,4]$. The contribution of melting snow and glacier runoff accounting for the total river runoff ranged from $20 \%$ to $70 \%$ in the region $[5,6]$. The volume of the glaciers is about $811.2 \mathrm{~km}^{3}$ in the Qi Lian Mountains, and the annual average runoff that flows from the mountains is about $71 \mathrm{~km}^{3}$, which irrigates about $7800 \mathrm{~km}^{2}$ of farmland and supports more than 500 million people [7]. It is evident that the water resources of the Tien Shan and Qi Lian Mountains are the lifeblood of the ecosystems and human population in the arid lands of northwest China.

Changes of the water balance factors (precipitation, runoff, and evaporation) have become an important topic of research in the mountains of arid northwest China [8]. A significant increasing trend of temperature has also been observed in the mountains of northwest China $[9,10]$. Climate change will undoubtedly influence surface process of runoff in arid and semiarid areas, especially on the scale of the basins [11]. Researches indicated that runoff, temperature, and precipitation had shown significant increasing trends from 1957 to 2007 in Manas, Jing, Tarim, Kaidu, and Urumqi river basins which were located in the Tien Shan Mountains [12-14]. During 1950-2000, precipitation showed an increasing trend in the Qian Lian Mountains, but runoff showed 
a significant decreasing trend in the eastern region of the mountains (Shiyang River and Taolai River). Furthermore, the trend of runoff change was not obvious in central and western parts, although precipitation and temperature showed simultaneous rising trends (e.g., He River and Shule River) [15-18]. Evaporation also plays an important role in the water balance in northwest China. Some researchers have indicated that evaporation has shown a trend of decrease in the Tien Shan and Qi Lian Mountains $[19,20]$. Changes of evaporation cause changes in other factors (e.g., precipitation, runoff, and terrestrial water storage change (TWSC) of the water balance). Most previous researches in the mountains of arid northwest China have focused on precipitation, runoff, and evaporation; however TWSC has been ignored. Therefore, systematic changes in the factors of the terrestrial water balance were still unknown in the arid mountains.

TWSC which is essential and important for understanding a wide range of hydrological, climatological, ecological processes and water resource management includes changes of surface water, snow and ice, soil moisture, and groundwater [21]. It is difficult to measure TWSC directly, especially in remote mountains. In tradition, satellites can be used to detect surface soil moisture in which the depth was only about ten centimeters. Besides, the spatial distribution of field stations for verification purposes is poor. However, the Gravity Recovery and Climate Experiment (GRACE) satellites can make up such disadvantages; it offers a new opportunity for quantitative studies of regional TWSC.

The GRACE detects the variation of the Earth's global gravity field which is mainly due to land TWSC, such as ice masses (e.g., polar ice sheets, alpine glaciers, and ice caps) and other geophysical signals (e.g., postglacial rebound and deformation caused by earthquakes) [22, 23]. Interference signals in the GRACE data caused by atmospheric and oceanmass variations can be removed successfully using numerical simulations, and then TWSC was retrieved [24]. The GRACE satellites can monitor the water equivalent change about $0.9 \mathrm{~cm}$ and the precision can reach $1-1.5 \mathrm{~cm}$ when spatial scales are longer than $1300 \mathrm{~km}[25,26]$. Some researchers have compared the results between retrieved by GRACE and using global land-surface-process models. The two methods have shown similar results in most areas, although some discrepancies arose owing to difficulties in obtaining precise input data in models. TWSC retrieved by GRACE can provide the reference for improvements of the accuracies of global land-surface-process models [27-30]. Besides, GRACE data have also been applied to monitor soil moisture and groundwater depletion due to drought or irrigation [31-34] and extract flux information from the water balance equation, such as evapotranspiration $[35,36]$ or river discharge [3740]. In addition, TWSC data retrieved by GRACE have been used in cryospheric-related research on permafrost activities in Alaska, Arctic, central Siberia regions, and Three-River Source Region of the Tibetan Plateau, indicating that changes in the permafrost active layer might be an important reason behind the variations of TWSC in these areas [41-44]. In China, researches have focused on large areas $[5,30,45$, 46]. Generally, the researches involved regional quantitative descriptions of TWSC which just reveal characteristics in

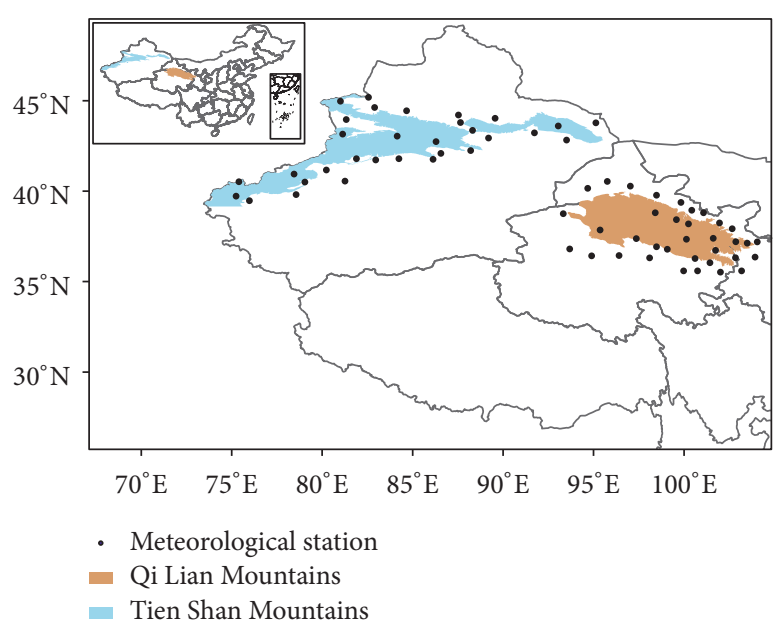

Figure 1: Locations of the Tien Shan Mountains and Qi Lian Mountains.

different area. However, a comprehensive study of WSC in the mountains of arid northwest China has not been reported previously.

In this study, gravity information retrieved from GRACE satellites was used to assess monthly TWSC during 2003 to 2010 in the Tien Shan and Qi Lian Mountains. This investigation focused on the influence of permafrost and glaciers on TWSC, changes in TWSC related to different mountains, and water balance changes in the study area. The purpose of this work is preliminary to reveal the basic law of water recycling and provide a baseline for water resource management in the arid northwest China.

\section{Study Area}

The study area encompassed the Tien Shan Mountains and Qi Lian Mountains, which are located in arid northwest China (Figure 1). The Tien Shan Mountains in the hinterland of Asia are located within $39-45.5^{\circ} \mathrm{N}$ and $73-96^{\circ} \mathrm{E}$. They stretch $1700 \mathrm{~km}$ from east to west and cover an area of about 27.1 $\times 10^{4} \mathrm{~km}^{2}$. There are 9035 glaciers with the area of about $9225 \mathrm{~km}^{2}$, accounting for $3.41 \%$ of the total area. The area of permafrost is about $6.3 \times 10^{4} \mathrm{~km}^{2}$, which accounts for $23 \%$ of the total area [18]. The Tien Shan Mountains are located in an inland area affected by the mid-latitude westerlies, and thus the main source of water vapor is from the westerly circulation. The remaining water vapor $(1 / 4-1 / 3)$ is brought by dry and cold Arctic air, and the impact of the Pacific and the Indian Ocean monsoons is small [47]. The Tien Shan Mountains constitute the main water source for the Chinese province of Xinjiang. Although the area of Tien Shan Mountains only accounts for $16.3 \%$ of the total area in the Chinese province of Xinjiang, they provide $40 \%$ of total water resources. The area of northern and southern slopes of Tien Shan Mountains is $11.7 \times 10^{4}$ and $15.4 \times 10^{4} \mathrm{~km}^{2}$, respectively, which accounts for about $43 \%$ and $57 \%$ of the total area. Average annual precipitation on the northern and southern slopes is about 591 and $396 \mathrm{~mm}$, respectively [48]. 
The Qi Lian Mountains are located in the northeastern edge of the Tibetan Plateau $\left(36-40^{\circ} \mathrm{N}, 93.5-103.1^{\circ} \mathrm{E}\right)$ (Figure 1). The length of the Qi Lian Mountains is about $850 \mathrm{~km}$, and the total area is about $19.8 \times 10^{4} \mathrm{~km}^{2}$. There are 2859 glaciers, whose area is $1972.5 \mathrm{~km}^{2}$, and it accounts for $1 \%$ of the total area. The area of permafrost is about $10 \times 10^{4} \mathrm{~km}^{2}$, which accounts for about $50 \%$ of the total area [15]. Qi Lian Mountains are the most important water source for the inland rivers (Shiyang River, He River, Shule River, Datong River, and Qinghai lake) in Hexi Corridor, and thus they constitute an important factor for the regional population and socioeconomic development. The eastern Qi Lian Mountains are affected by the southwest and southeast summer monsoons. Because of the steep slopes, air rises vigorously and annual precipitation is more in this area. Middle and western parts of the Qi Lian Mountains are further from the ocean and consequently, annual precipitation is smaller than in the eastern part. Overall, the average annual temperature decreases gradually with increasing elevation, precipitation decreases from east to west, and the climate ranges from semihumid to semiarid and arid [48].

\section{Data and Methods}

3.1. Method of TWSC Data Retrieval. This study used GRACE Level-2 RL05 data from the University of Texas Centre for Space Research (http://www.csr.utexas.edu/grace/asdp.html), and the resolution of gridded data is $1^{\circ} \times 1^{\circ}$. As the reference frame used in the determination of GRACE satellites gravity field, gravity field coefficients of degree 1 in RL05 were processed as zero. However, the degree 1 information could have significant impact on the recovery of surface mass variations. To improve the accuracy and precision in deriving TWSC, the original gravitational coefficients of degree 1 were replaced by calculated values in RL05 [49]. RL05 data, with the same signals in RL04, has been improved with significant noise reduction. Given that the C20 coefficient which is measured by satellite laser ranging (SLR) is much better than in RL05, so C20 was replaced with SLR C20 in RL05 [50]. A decorrelation filter was applied to reduce the effects of noisy $\mathrm{N}-\mathrm{S}$ stripes in the monthly time-variable coefficients. Correlated noises (N-S stripes) were removed from coefficients for orders $(m)$ greater than 15 which used a fifth-order polynomial, and it was fitted as a function for each odd or even set for a given order [49]. These processed spherical harmonic coefficients were transformed into gridded data with 1-arc-degree spatial resolution, indicating the Earth's surface mass variations, which were caused mainly by the redistribution of water on continents or in oceans. The global grids comprised 1-arcdegree water equivalent mass change complete to degree and order 40. The GRACE Level-2 RL05 data (300 km Gausssmoothing kernel) land and ocean monthly grids during 2003 to 2010 were combined to provide global coverage [51]. Glacial isostatic adjustment (GIA) is ongoing movement of land, and the land once under and around the ice is still rising and falling in reaction to its ice-age burden (http:// oceanservice.noaa.gov/facts/glacial-adjustment.html), and we deal with the GIA in study area by the method of Paulson et al. [52]. The process of retrieving is given by:

$$
\begin{gathered}
\Delta h(\phi, \lambda, t)=\frac{a_{e} \rho_{e}}{3 \rho_{w}} \sum_{l=0}^{40} \sum_{m=0}^{l} \frac{(2 l+1)}{1+k_{l}} W_{l} P_{l m} \sin (\phi) \\
\cdot\left[\Delta C_{l m}(t) \cos (m \lambda)+\Delta S_{l m}(t) \sin (m \lambda)\right], \\
W_{l}=\exp \left[\frac{\left(\operatorname{lr} / a_{e}\right)^{2}}{4 \ln (2)}\right],
\end{gathered}
$$

where $P_{l m}$ is normalized Legendre polynomials, $\Delta C_{l m}(t)$ and $\Delta S_{l m}(t)$ are normalized time-varying stokes spherical harmonic geopotential coefficients, $a_{e}$ is Earth's mean radius, $r$ is the spatial radius, $k_{l}$ are Love numbers, $\rho_{e}$ is Earth's mean density, $\rho_{w}$ is water density, $t$ is time, and $\phi$ and $\lambda$ are latitude and longitude, respectively.

3.2. Precipitation Data and Spatial Interpolation Method. Precipitation data were obtained from national meteorological stations within the study area during 2003 to 2010, and the data was corrected which considers the influence of wind [53]. Furthermore, to improve the continuous spatial extent of precipitation, the data were interpolated using Kriging with consideration of elevation [54]. This method uses precipitation and site elevation data to perform an initial linear regression. The spatial rasterized precipitation regressed by elevation $P_{r}$ was calculated using the formula for linear regression, and the residuals (regressed precipitation minus measured precipitation) were interpolated using the Kriging spatial interpolation method, and then the values of the spatial $P_{r}$ were added to the spatial residuals, providing the spatial distribution of precipitation:

$$
P_{\text {result }}=P_{r}+P_{\text {residual }} \text {, }
$$

where $P_{\text {result }}$ is the spatial precipitation, $P_{r}$ is the rasterized precipitation regressed by elevation, and $P_{\text {residual }}$ is the spatial residual (units: $\mathrm{mm}$ ).

3.3. Change of Precipitation. Precipitation is the main source of land surface water, and changes in precipitation affect evaporation, runoff, and TWSC. In this study, the change of precipitation was calculated using the following formula:

$$
P_{c}=P_{i}-P_{i-1} \text {, }
$$

where $P_{c}$ is the change of precipitation, $P_{i}$ is the precipitation in month $i, P_{i-1}$ is the precipitation in the preceding month, and $i$ represents the month (1-12). And then we calculate the average annual change of precipitation from 2003 to 2010.

3.4. Basin-Scale Water Balance. The basic elements of water cycle include precipitation, runoff, evaporation, and water storage change in watershed. Runoff is relatively easy to obtain in scale of watershed. However, the total runoff of remote mountain region is more difficult to obtain. Actual evaporation $\left(\mathrm{ET}_{a}\right)$ is an important factor in studies of hydrology, and it can be estimated indirectly using physical models 


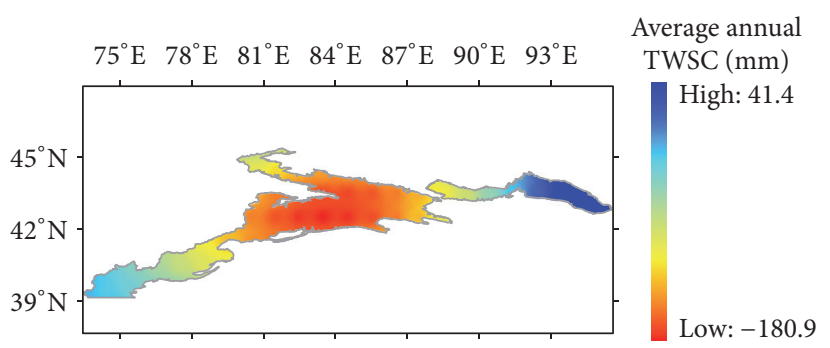

(a)

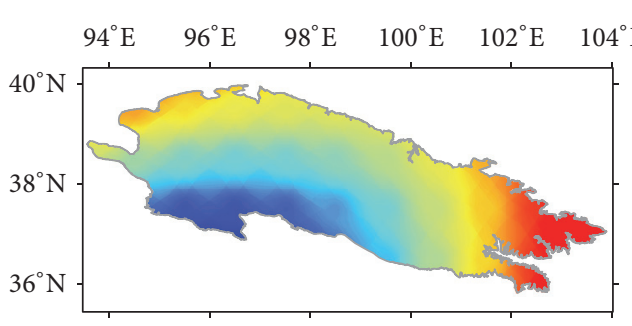

(c) TWSC (mm)

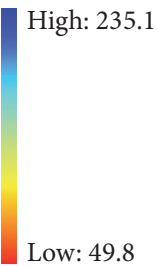

Low: 49.8

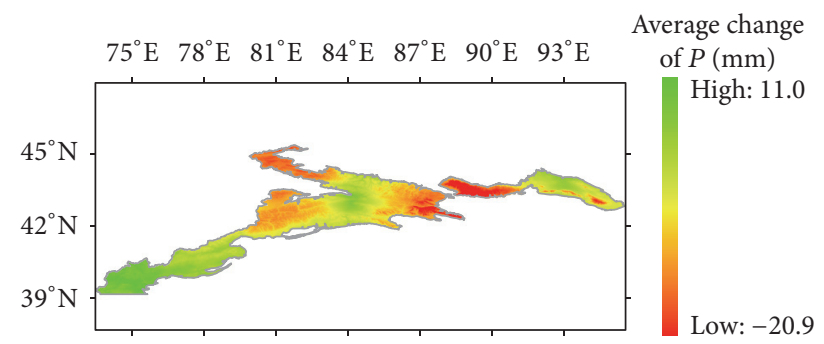

(b)

Average annual

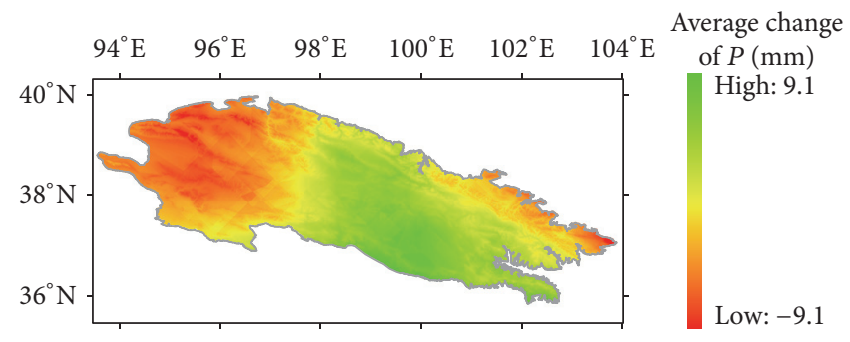

(d)

FIGURE 2: Spatial distribution of mean annual terrestrial water storage change (TWSC) and mean annual change of precipitation $(P)$ over the Tien Shan Mountains (a, b) and Qi Lian Mountains (c, d) during 2003 to 2010.

(e.g., the Penman-Monteith equation). Based on the riverbasin-scale terrestrial water balance, changes of regional runoff can be estimated by TWSC, precipitation, and $\mathrm{ET}_{a}$. In the equation of water balance, the TWSC can be retrieved by GRACE, the precipitation can be measured by rain gauge, and $\mathrm{ET}_{a}$ was calculated by Penman-Monteith equation. Within a closed area, changes in the various elements of the water cycle determine the regional water cycle characteristics. The water balance equation was used to calculate $\Delta R$, and it can be expressed as

$$
\Delta R=\Delta P-\Delta \mathrm{ET}_{a} \pm \Delta W
$$

where $\Delta R$ is the change of runoff, $\Delta P$ is the change of precipitation, $\Delta \mathrm{ET}_{a}$ is the change of actual evaporation, and $\Delta W$ is the TWSC of the watershed, which can be retrieved by GRACE.

3.5. Trend of TWSC. The trend represents the spatial variation of slope. A positive slope indicates TWSC increased and a negative slope indicates that TWSC decreased. We calculated the interannual slope for the Tien Shan and Qi Lian Mountains using the following equation [55]:

$$
=\frac{8 \times \sum_{i=1}^{8} i \times \mathrm{GRACE}_{i}-\left(\sum_{i=1}^{8} i\right)\left(\sum_{i=1}^{8} \mathrm{GRACE}_{i}\right)}{8 \times \sum_{i=1}^{8} i^{2}-\left(\sum_{i=1}^{8} i\right)^{2}}
$$

where slp is the spatial variation of slope and $\mathrm{GRACE}_{i}$ is the TWSC in year $i$; for example, 2003 is the first year, 2004 is the second year, and so on.

\section{Results and Discussion}

4.1. Temporal and Spatial Patterns of TWSC and Precipitation over the Tien Shan and Qi Lian Mountains. The TWSC was retrieved from GRACE satellites data during 2003 to 2010 in the Tien Shan and Qi Lian Mountains. The spatial distributions of the average annual TWSC and change of precipitation calculated using (2) and (3) are shown in Figure 2. The average annual TWSC of the Tien Shan Mountains is in a state of gain in the west and east, but in a state of loss in central parts. The magnitude of TWSC in the west and east of the Tien Shan Mountains is smaller than in central parts. The ranges of TWSC and precipitation changes are from $-180.9 \mathrm{~mm}$ to $41.4 \mathrm{~mm}$ and $-20.9 \mathrm{~mm}$ to $11.0 \mathrm{~mm}$ during 2003 to 2010, respectively. The spatial distributions of TWSC are consistent with precipitation, which indicates that the spatial distribution of TWSC is influenced by precipitation in the western and eastern Tien Shan Mountains and even in some central parts. However, they also show opposite distributions in central and some eastern areas (Figures 2(a) and 2(b)), which is mainly because of the more demands for water for agricultural use from these area, and more groundwater extraction for irrigation leads to the state of loss of TWSC. Even though the change of precipitation is positive in these areas, rising temperatures accelerated glacial melt, which fed the rivers, and thus the TWSC remained in a state of loss. Research has indicated that the average loss of mass balance was about $267 \mathrm{~mm}$ in number 1 glacier in Urumuqi river over the Tien Shan during 1959 to 2009 [56, 57], and the TWSC of the Tien Shan Mountains might reflect the partial loss of the glaciers.

The TWSC was in a state of gain throughout the Qi Lian Mountains during 2003 to 2010 (Figures 2(c) and $2(d))$, but the spatial distribution of TWSC shows significant differences; that is, it is more in the west than in east, and 


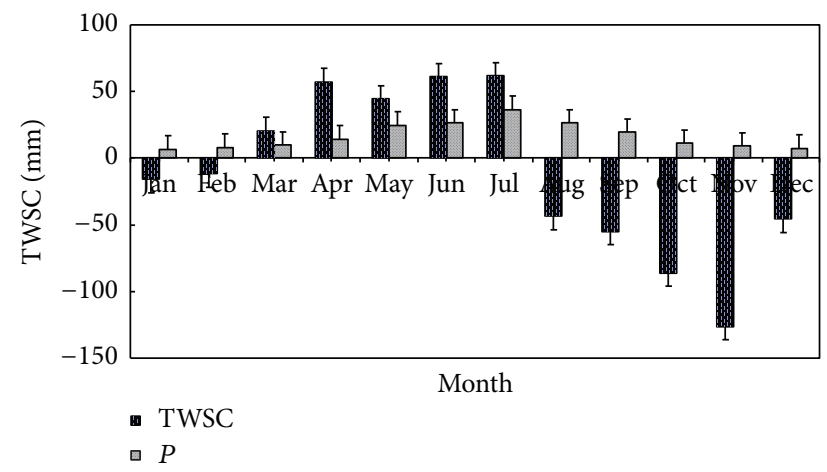

(a)

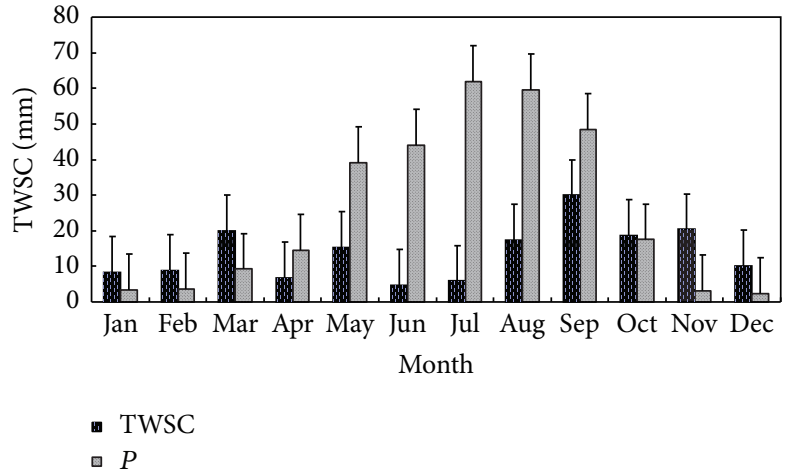

(b)

FIgURE 3: Annual distributions of terrestrial water storage change (TWSC) and precipitation during 2003 to 2010: (a) Tien Shan Mountains and (b) Qi Lian Mountains.

more in the south than in the north. The maximum value is in the south and the minimum value in the east. Precipitation changed little during 2003 to 2010, and it decreased in western areas and decreased slightly in the northeast but increased in most central parts (Figure 2(d)). The ranges of TWSC and precipitation changes are from $49.8 \mathrm{~mm}$ to $235.1 \mathrm{~mm}$ and $-9.1 \mathrm{~mm}$ to $9.1 \mathrm{~mm}$ during 2003 to 2010 , respectively. There are differences between the spatial distributions of TWSC and precipitation change, which indicate that the distribution of TWSC is not only influenced by precipitation but also by the underlying surface. The maximum value appears on the southern slopes of central parts, because the TWSC is controlled by the presence or absence of permafrost and the thickness of the active layer of permafrost in this region. Here, surface water was recruited for subsurface groundwater storage and increasing groundwater residence time led to the increase of the TWSC, as it has been similarly confirmed in the Arctic [58-60].

TWSC and precipitation have obviously seasonal variations in the Tien Shan and Qi Lian Mountains, and the distribution of TWSC exhibits different characteristics (Figures 3(a) and 3(b)). The study areas are located in different parts of northwest China where the sources of water vapor depend mainly on the zonal westerly circulation (Tien Shan and Qi Lian) and the East Asian monsoon (Qi Lian) [61, 62]. Rainfall is concentrated mainly from May to October in study area. The peak values of TWSC and precipitation appear at the same time (July) in the Tien Shan Mountains. The gain of TWSC is concentrated mainly during March to July in the Tien Shan Mountains, the end of which is the period of maximum precipitation (maximum value of average monthly TWSC is $61.7 \mathrm{~mm}$ in July) during 2003 to 2010. The value of TWSC in the Tien Shan Mountains is larger than precipitation from March to July. Conversely, the TWSC in the Tien Shan Mountains is in a state of loss during the other months; for example, the minimum value is $-126.3 \mathrm{~mm}$ in November during 2003 to 2010. There are two peaks of TWSC in the Qi Lian Mountains (March and September). In spring, because of the thawing and refreezing of permafrost, precipitation is stored in the mountains, which leads to the peak in the TWSC in the Qi Lian Mountains. However, over time, runoff is generated and the WSC decreases. With the arrival of the rainy season, the second peak appears, although the process of TWSC has a certain lag compared with the process of precipitation, which indicates that permafrost might play a decisive role in the formation of cold groundwater transport processes and the pattern of distribution of groundwater and its pathways in the Qi Lian Mountains. The TWSC is in a state of gain during January to December in the Qi Lian Mountains, and the maximum value is in September $(20.4 \mathrm{~mm})$ and the minimum value is in June $(6.7 \mathrm{~mm})$.

The process of TWSC is consistent with the process of precipitation during 2003 to 2010 in the Tien Shan Mountains (Figure 4(a)). The variation of TWSC ranged from $-98.4 \mathrm{~mm}$ to $41.5 \mathrm{~mm}$ during 2003 to 2010 in Tien Shan Mountains. This means that the maximum increase in water was about $41.5 \mathrm{~mm}$ equivalent water height and the minimum value was $-98.4 \mathrm{~mm}$ equivalent water height. Monthly precipitation ranges from 2.8 to $53.7 \mathrm{~mm}$, although there is little variation in the annual precipitation during 2003 to 2010 (Figure 4(a)). The characteristics of the variation in precipitation have the dominant effect on TWSC in the time series, especially in 2008 and 2009 (i.e., less precipitation and lower TWSC). TWSC shows a significant decreasing trend during 2003 to 2010, which means that the difference between the water flowing into and out of the region fell (Table 1).

The process of TWSC is more complicated in the Qi Lian Mountains, although there is little variation in the annual precipitation in the Qi Lian Mountains during 2003 to 2010 (Figure 4(b)). The variation of TWSC ranges from $-59.3 \mathrm{~mm}$ to $96.3 \mathrm{~mm}$ and variation of precipitation ranges from $0.9 \mathrm{~mm}$ to $72.2 \mathrm{~mm}$ in Qi Lian Mountains during 2003 to 2010. The minimum and maximum values in the Qi Lian Mountains are all larger than in the Tien Shan Mountains, which means the distribution of water resource is uneven in the Qi Lian Mountains and that water resources in the Tien Shan Mountains are even scarcer. The TWSC shows a 


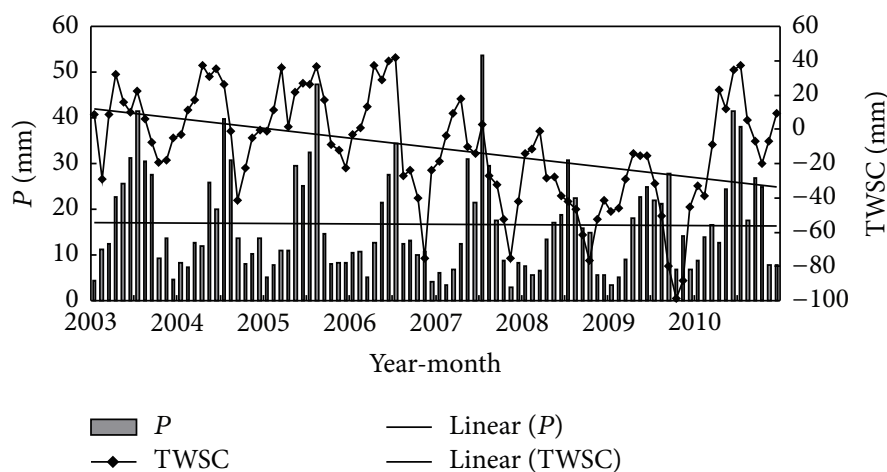

(a)

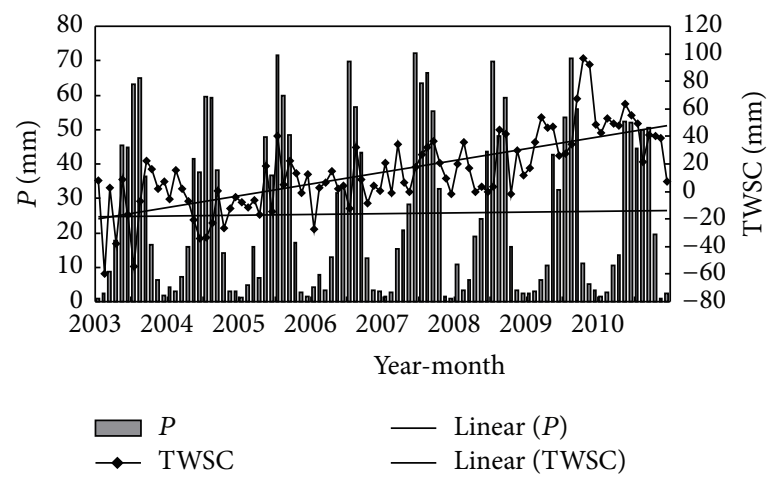

(b)

FIGURE 4: Time series of terrestrial water storage change (TWSC) and precipitation $(P)$ during 2003 to 2010: (a) Tien Shan Mountains and (b) Qi Lian Mountains.

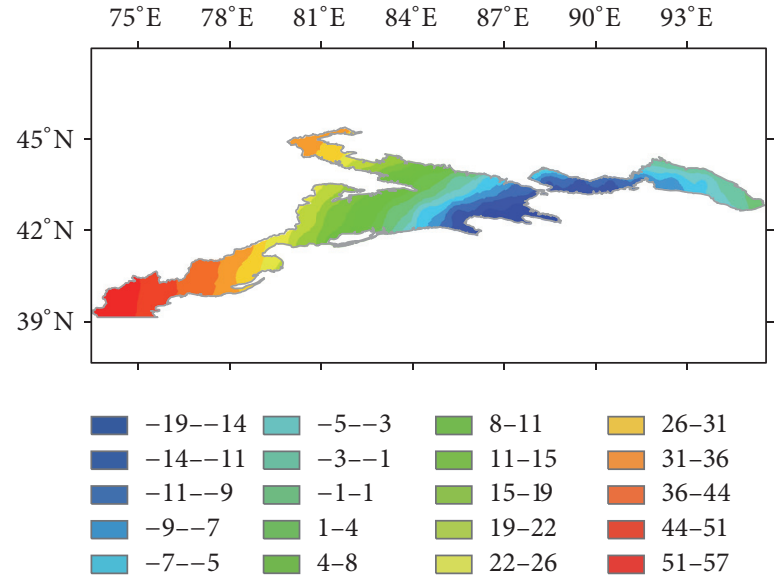

(a)

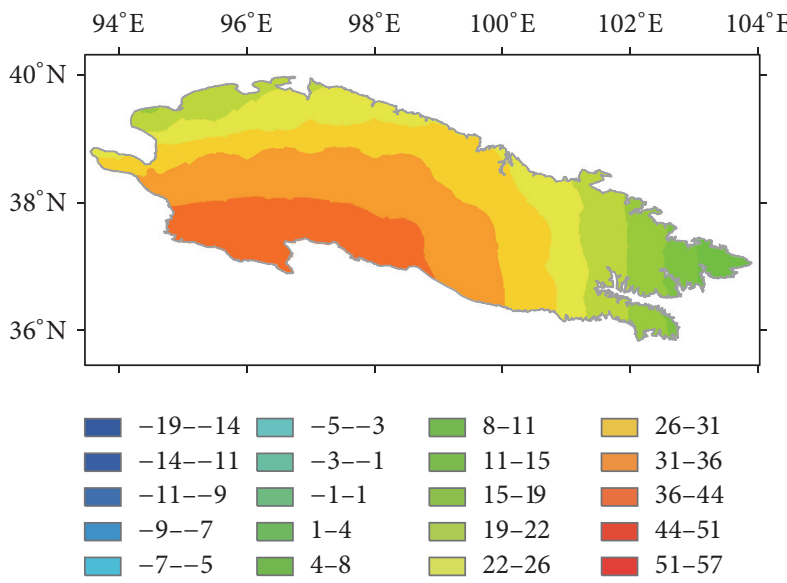

(b)

FIGURE 5: Spatial trends of terrestrial water storage change (TWSC) during 2003 to 2010: (a) Tien Shan Mountains and (b) Qi Lian Mountains.

TABLE 1: Amount of terrestrial water storage change (TWSC) in the Tien Shan Mountains and Qi Lian Mountains during 2003 to 2010.

\begin{tabular}{lcc}
\hline Region & $\begin{array}{c}\text { Rate of change } \\
(\mathrm{mm} / \text { year })(p<0.05)\end{array}$ & $\begin{array}{c}2003-2010 \text { TWSC } \\
\left(\mathrm{km}^{3}\right)\end{array}$ \\
\hline Tien Shan Mts. & $-5.8 \pm 1.1$ & $-12.5 \pm 2.3$ \\
Qi Lian Mts. & $8.6 \pm 0.8$ & $13.6 \pm 1.3$ \\
\hline
\end{tabular}

significant increasing trend during 2003 to 2010, which means that more water is stored in the Qi Lian Mountains (Table 1).

\subsection{Spatial Trends and Cycles of TWSC over the Tien Shan} and Qi Lian Mountains. The spatial trends of TWSC during 2003 to 2010 in the Tien Shan and Qi Lian Mountains were calculated using (5) and are illustrated in Figures 5(a) and 5(b), respectively. There is a positive trend in the west and a negative trend from central parts to the east in the Tien Shan Mountains. The minimum value of the trend appears in central parts of the Tien Shan Mountains (Figure 5(a)). The spatial trends of TWSC during 2003 to 2010 in the Qi Lian Mountains are all positive (Figure 5(b)), and the maximum value appears on the southern slopes and the minimum value is in the east. A comparison of the two regions shows uneven distribution of TWSC in the Tien Shan Mountains and more abundant water resource in the Qi Lian Mountains (Figures 5(a) and 5(b)). The TWSC retrieved by GRACE are in line with normal patterns (Figure (4)). The change of water storage change in the Tien Shan Mountains has greater complexity and uncertainty. For one thing, water storage change is more scarce and needs more time to supplement. And although the TWSC of the area has increased overall, a greater quantity of water is stored in the Qi Lian Mountains.

\subsection{The Influences of Permafrost and Glaciers on TWSC in the} Tien Shan and Qi Lian Mountains. As shown in Figure 6, precipitation in the two mountain areas does not change much during 2003 to 2010, but the pattern of TWSC is very different. During 2003 to 2005 and in 2010, TWSC is in a state of gain in the Tien Shan Mountains (maximum value appears in 2005: $132.2 \mathrm{~mm}$ ), and during 2006 to 2009, TWSC is in a state of loss (minimum value appears in 2009: $-561.5 \mathrm{~mm}$ ). In the Qi Lian Mountains, WSC is only in a state of loss in 2003 and 2004, and it is in a state of gain in other years 


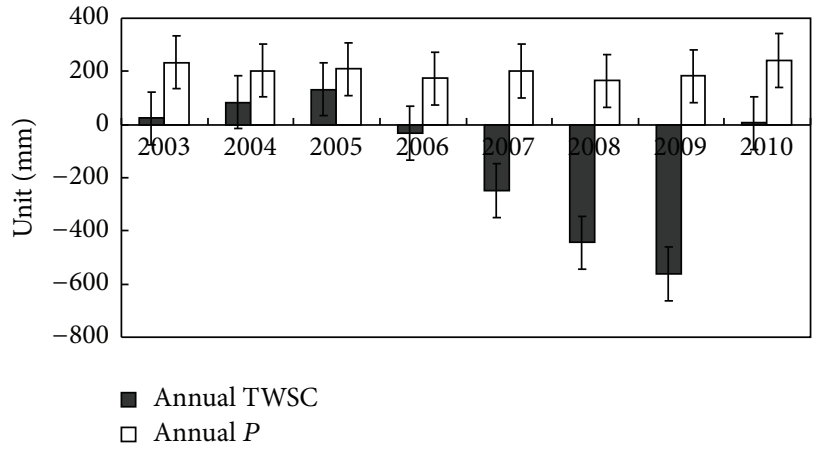

(a) Tien Shan

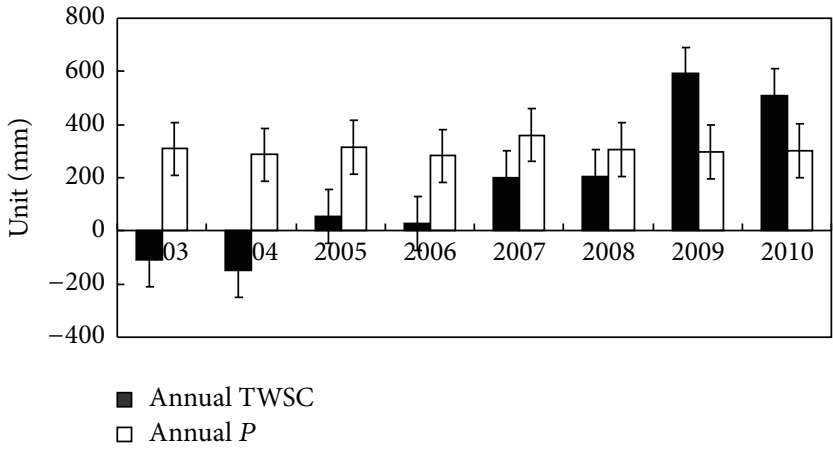

(b) Qi Lian

FIgURE 6: Annual terrestrial water storage change (TWSC) and precipitation $(P)$ in the Tien Shan and Qi Lian Mountains.

(maximum and minimum values are $591.7 \mathrm{~mm}$ (2009) and $22.9 \mathrm{~mm}$ (2003), resp.). The distributions of glaciers, permafrost, and talik (a layer of ground that remains unfrozen year-round) affect the characteristics of surface drainage and groundwater storage changes in northwest China [39]. The dynamics of permafrost, talik, and the active layer exert significant influence on the surface and groundwater hydrology and geomorphology in the Qi Lian Mountains. The Qi Lian Mountains is the region of numerous and quite large thermokarst thaw ponds, lakes, and drained thaw-lake basins $[63,64]$. The increase and thickening of the active layer can lead to greater infiltration of surface water into the groundwater, which results in increased water storage. The GRACE monthly water equivalent changes capture the changes of the base flow from groundwater and surface water into the permafrost area.

In related research, GRACE-derived TWSC has been found to increase in the watershed of the Lena and Yenisei rivers [65]. These watersheds encompass large areas of both continuous and discontinuous permafrost zones and talik. Glacier mass loss has occurred across the QL and Tien Shan Mountains [66]; however, since the early 2000s, the trend of precipitation has not changed much. In contrast, TWSC has exhibited large differences (Figure 6). TWSC decreased in Tien Shan Mountains, but it increased in Qi Lian Mountains. The total area of the Tien Shan Mountains is $27.1 \times 10^{4} \mathrm{~km}^{2}$, and the area of glaciers is approximately $9225 \mathrm{~km}^{2}$ which accounts for $3.41 \%$ of the total area. The area of permafrost is about $6.3 \times 10^{4} \mathrm{~km}^{2}$ which accounts for $23 \%$ of the total area. The area of the Qi Lian Mountains is $19.8 \times$ $10^{4} \mathrm{~km}^{2}$, and the area of glaciers is approximately $1931 \mathrm{~km}^{2}$, which accounts for about $1 \%$ of the total area. The area of permafrost is about $10 \times 10^{4} \mathrm{~km}^{2}$, which accounts for $50 \%$ of the total area. In the Tien Shan and Qi Lian Mountains, meltwater is the primary supplement to runoff. However, the TWSC is in a state of loss in the Tien Shan Mountains, which shows that glacial meltwater flows out of this area and less surface water infiltrates into the groundwater. The Qi Lian Mountains have a greater distribution of permafrost than the Tien Shan Mountains, and thus the thickened active layer, as well the greater number of ponds, might store additional water that causes the increase of WSC (Figure 7).

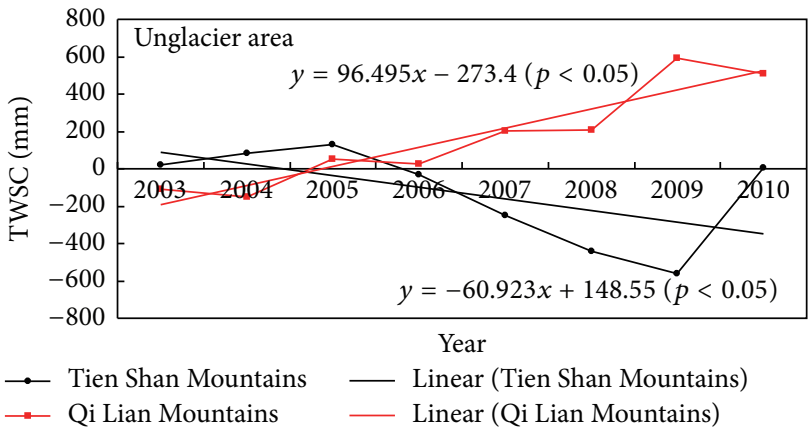

FIGURE 7: Terrestrial water storage change (TWSC) of nonglaciated areas of the Tien Shan and Qi Lian Mountains.

TABLE 2: Average rates of water balance parameter change in the Tien Shan Mountains and Qi Lian Mountains during 2003 to 2010.

\begin{tabular}{lcccc}
\hline Region & $\begin{array}{c}\Delta P \\
(\mathrm{~mm} / \text { year })\end{array}$ & $\begin{array}{c}\Delta E \\
(\mathrm{~mm} / \text { year })\end{array}$ & $\begin{array}{c}\Delta W \text { (TWSC) } \\
(\mathrm{mm} / \text { year })\end{array}$ & $\begin{array}{c}\Delta R \\
(\mathrm{~mm} / \text { year })\end{array}$ \\
\hline Tien Shan & -0.1 & $-2.5[20]$ & -5.8 & +8.5 \\
Mts. & & $-1.7[19]$ & +8.6 & -6.7 \\
Qi Lian Mts. & +0.2 & -6.7
\end{tabular}

TABlE 3: Changes of water balance parameter in the Tien Shan Mountains and Qi Lian Mountains during 2003 to 2010.

\begin{tabular}{lcccc}
\hline Region & $\begin{array}{c}\Delta P \\
\left(\mathrm{~km}^{3}\right)\end{array}$ & $\Delta E\left(\mathrm{~km}^{3}\right)$ & $\begin{array}{c}\Delta W(\mathrm{TWSC}) \\
\left(\mathrm{km}^{3}\right)\end{array}$ & $\Delta R\left(\mathrm{~km}^{3}\right)$ \\
\hline Tien Shan & -0.2 & -5.4 & -12.5 & +17.7 \\
Mts. & -0.2 & -2.7 & +13.6 & -10.6 \\
Qi Lian Mts. & +0.4 & -4.6 \\
\hline
\end{tabular}

\subsection{Changes of Water Balance in the Tien Shan and Qi Lian} Mountains. Changes of the water balance were analyzed in the Tien Shan and Qi Lian Mountains during 2003 to 2010 and the results are presented in Tables 2 and 3. Precipitation in the study area shows different trends. The rate of decrease is $-0.1 \mathrm{~mm} /$ year in the Tien Shan Mountains, which is equivalent to a water volume of $-0.2 \mathrm{~km}^{3}$ during 2003 to 2010 . The rate of increase in the Qi Lian Mountains is $0.2 \mathrm{~mm} /$ year. Evaporation shows the same trend. Evaporation in the Tien 
Shan and Qi Lian Mountains shows decreasing trends in recent decades which is $-2.5 \mathrm{~mm} /$ year and $-1.7 \mathrm{~mm} /$ year, respectively, and they are equivalent to water volumes of $-5.4 \mathrm{~km}^{3}$ and $-2.7 \mathrm{~km}^{3}$ during 2003 to 2010 , respectively. The changes of water balance in the two mountain regions can be calculated using (4). The rates and volumes of $\Delta P$, $\Delta E, \Delta W$, and $\Delta R$ within the study area are given in Tables 2 and 3. The trend of $\Delta R$, although of similar magnitude, is opposite sign (decrease) relative to the trend determined using GRACE (increase). The increase of $\Delta R$ in the Tien Shan Mountains is $8.5 \mathrm{~mm} /$ year $\left(17.7 \mathrm{~km}^{3}\right)$ and the decrease of $\Delta R$ in the Qi Lian Mountains is $-6.7 \mathrm{~mm} /$ year $\left(-10.6 \mathrm{~km}^{3}\right)$ during 2003 to 2010 . In all cases, the precipitation trends are clearly lower than those derived from GRACE. This indicates that precipitation is not the dominant component of short-term TWSC in the Tien Shan and Qi Lian Mountains. Changes in the water balance of the study area were mainly related to changes of TWSC and runoff, which were influenced by the distributions of glaciers and permafrost as discussed above.

\section{Conclusions}

The TWSC was retrieved using GRACE data during 2003 to 2010 in the Tien Shan and Qi Lian Mountains. The spatial distribution of WSC was more influenced by precipitation in the Tien Shan Mountains than in the Qi Lian Mountains. Permafrost and glaciers of mountains play an important role in the water cycle of arid land, and the increase and thickening of the active layer can lead to more infiltration of surface water into the groundwater, which can result in increased water storage and changes in the regional water balance.

In the Tien Shan Mountains, the TWSC decreased obviously during 2003 to 2010 with an average rate of decrease of about $-5.8 \pm 1.1 \mathrm{~mm} /$ year $(p<0.05)$ (a total decrease of $-12.5 \pm 2.3 \mathrm{~km}^{3}$ ). In the Qi Lian Mountains, the TWSC increased during 2003 to 2010 with an average rate of increase of about $8.6 \pm 0.8 \mathrm{~mm} /$ year $(p<0.05)$ (a total increase of $13.6 \pm 0.8 \mathrm{~km}^{3}$ ). We try a new method to estimate runoff based on water balance. Runoff increased in the Tien Shan Mountains during 2003 to 2010 at a rate $8.5 \mathrm{~mm}$ /year, which is $17.7 \mathrm{~km}^{3}$, but it decreased in the Qi Lian Mountains at a rate of $-6.7 \mathrm{~mm} /$ year, which is $-10.6 \mathrm{~km}^{3}$. In cases of little changes in precipitation and evaporation in short time, the increase (decrease) of WSC was significant, which caused a decrease (increase) in runoff from the mountains of northwest China.

GRACE can reveal trend of water storage change in large and middle scale area, and it is the complement for elements of water cycle in monitoring techniques which have existed (e.g., dig wells and remote sensing technology). With the improvement of retrieved method and implementing a follow-on satellite gravity exploration program, spatial resolution and accuracy of global and regional water storage changes will be further enhanced. The GRACE data was assimilated with surface ecological environmental multisources, multiscale observations which can reveal the variation of hydrological cycle and its response to climate change.

\section{Competing Interests}

The author declares that they have no competing interests.

\section{Acknowledgments}

This study was supported by National Natural Science Foundation of China (41690141, 41501073, and 41421061), the National Basic Research Program of China (973 Program, 2013CBA01806), the Chinese Academy of Sciences (KJZD-EW-G03-04), China Postdoctoral Science Foundation (2016T90966, 2015M580893), and Natural Science Foundation of Gansu Province (1606RJZA104).

\section{References}

[1] L. Guo and L. Li, "Variation of the proportion of precipitation occurring as snow in the Tian Shan Mountains, China," International Journal of Climatology, vol. 35, no. 7, pp. 1379-1393, 2015.

[2] P. Wang, Z. Li, H. Li, L. Wu, S. Jin, and P. Zhou, "Changes of icethickness and volume for representative glaciers in Tianshan Mountains in the past 50 years," Acta Geographica Sinica, vol. 67, no. 7, pp. 929-940, 2012.

[3] Y. F. Shi, Glaciers and Related Environments in China, Science Press, Beijing, China, 2008.

[4] Y. C. Lan, S. F. Wu, P. Han, and Q. Zhao, "Change of water cycle factors in the Tianshan Mountain under global warming," Journal of Arid Land Resources \& Environment, vol. 22, no. 6, pp. 99-104, 2008.

[5] X. G. Hu, J. Chen, Y. Zhou, C. Huang, and X. H. Miao, "GRACE space gravity measurements to monitor the use of the Yangtze River seasonal changes in water storage," Science China: Earth Science, vol. 36, pp. 225-232, 2006.

[6] Y. Kong and Z. Pang, "Evaluating the sensitivity of glacier rivers to climate change based on hydrograph separation of discharge," Journal of Hydrology, vol. 434-435, pp. 121-129, 2012.

[7] J. Q. Chang, Z. R. Niu, and Q. Y. Wang, "Changes of water resources and ecological protection in Qilian Mountain," Gansu Water Conservancy and Hydropower Technology, vol. 45, no. 7, pp. 1-8, 2009.

[8] F. A. Abdulla, J. A. Amayreh, and A. H. Hossain, "Single event watershed model for simulating runoff hydrograph in desert regions," Water Resources Management, vol. 16, no. 3, pp. 221238, 2002.

[9] C. J. Zhang and N. Guo, "Climatic variation characteristics over Qilian Mountain area during the last 40 years," Meteorological Monthly, vol. 28, no. 12, pp. 33-37, 2002.

[10] H. Z. Pu, T. D. Han, P. Chen, X. Y. Li, and K. Q. Jiao, "Characteristics of air temperature in the southern and northern slopes of tianshan mountains," Plateau Meteorology, vol. 34, no. 3, pp. 753-761, 2015.

[11] Y. Chen, K. Takeuchi, C. Xu, Y. Chen, and Z. Xu, "Regional climate change and its effects on river runoff in the Tarim Basin, China," Hydrological Processes, vol. 20, no. 10, pp. 2207-2216, 2006.

[12] J. Q. Li, Y. N. Chen, W. H. Li, and Y. J. Chen, "Variation features of precipitation and runoff of the middle-small rivers 
of northern piedmont of Tianshan Mountains: a case of Jinghe River," Arid Land Geography, vol. 33, no. 4, pp. 615-622, 2010.

[13] Y. C. Lan, Y. J. Zhong, S. F. Wu, Y. P. Shen, G. Y. Wang, and L. C. Fang, "Response of mountain runoff to climate change in representative rivers originated from the Tianshan Mountain," Journal of Desert Research, vol. 31, no. 1, pp. 254-260, 2011.

[14] H. B. Ling, H. L. Xu, Q. Q. Zhang, and W. Shi, "The multi-time scale analysis on climate change and runoff processes in the Tianshan Mountains, Xinjiang," Journal of Natural Resources, vol. 26, no. 11, pp. 1908-1917, 2011.

[15] Y. J. Ding, B. S. Ye, and S. Y. Liu, "Impact of climate change on the alpine streamflow during the past 40a in the middle part of Qilian Mountains, Northwester China," Journal of Glaciolgy \& Geocryology, vol. 22, no. 3, pp. 193-199, 2000.

[16] Y. C. Lan, Y. Q. Wu, E. S. Kang, J. Zhang, and X. Hu, "Response of runoff from the northern slope of the qilian mountain to global climatic changes," Journal of Zhou University, vol. 37, no. 4, pp. 125-131, 2001.

[17] H. J. Wang, B. Zhang, X. H. Jin, H. Zhang, J. F. Liu, and S. P. Dai, "Spatio-temporal variations analysis of air temperature and precipitation in Qi Lian Mountainous Region based on GIS," Journal of Desert Research, vol. 29, no. 6, pp. 1198-1202, 2009.

[18] B. He, Y. Zhang, J. J. Zhu, S. Wei, and Z. Duan, "Analysis of the features of the mountainous runoff in three inland river basins of Qilian mountain during recent 50 years," Journal of Water Resources \& Water Engineering, vol. 22, no. 5, pp. 11-15, 2011.

[19] W.-X. Jia, Y.-Q. He, X.-F. Wang, and Z.-X. Li, “Temporal and spatial change of the potential evaporation over Qilian mountains and Hexi corridor from 1960 to 2006," Advances in Water Science, vol. 20, no. 2, pp. 159-167, 2009.

[20] M. J. Zhang, R. X. Li, W. X. Jia, and X. Wang, “Temporal and spatial changes of potential evaporation in tianshan mountains from 1960 to 2006," Acta Geographica Sinica, vol. 64, no. 7, pp. 798-806, 2009.

[21] G. Strassberg, B. R. Scanlon, and D. Chambers, "Evaluation of groundwater storage monitoring with the GRACE satellite: case study of the High Plains aquifer, central United States," Water Resources Research, vol. 45, no. 5, Article ID W05410, pp. 195211, 2009.

[22] B. D. Tapley, S. Bettadpur, J. C. Ries, P. F. Thompson, and M. M. Watkins, "GRACE measurements of mass variability in the Earth system," Science, vol. 305, no. 5683, pp. 503-505, 2004.

[23] M. Xu, S. Kang, and J. Li, "Evaluation of water storage change of Inland cryosphere in Northwestern China," Advances in Meteorology, vol. 2015, Article ID 681634, 12 pages, 2015.

[24] S. Bettadpur, GRACE Level-2 Gravity Field Product User Handbook, Center for Space Research, The University of Texas at Austin, Austin, Tex, USA, 2003.

[25] G. Ramillien, A. Cazenave, and O. Brunau, "Global time variations of hydrological signals from GRACE satellite gravimetry," Geophysical Journal International, vol. 158, no. 3, pp. 813-826, 2004.

[26] O. B. Andersen and J. Hinderer, "Global inter-annual gravity changes from GRACE: early results," Geophysical Research Letters, vol. 32, no. 1, pp. 1-4, 2005.

[27] D. D. Rowlands, S. B. Luthcke, S. M. Klosko et al., "Resolving mass flux at high spatial and temporal resolution using GRACE intersatellite measurements," Geophysical Research Letters, vol. 32, no. 4, pp. 319-325, 2005.

[28] J. B. Duan, M. Zhong, H. M. Yan, and M. Jiang, "Recovery of landwater storage varitions in Chinese Mainland by use of
GRACE data," Journal of Geodesy \& Geodynamics, vol. 27, no. 3, pp. 68-71, 2007.

[29] A. Güntner, "Improvement of global hydrological models using GRACE data," Surveys in Geophysics, vol. 29, no. 4-5, pp. 375397, 2008.

[30] X. Su, J. Ping, and Q. Ye, "Study on water storage change useing GRACE data in North China," Science China: Earth Science, vol. 42, pp. 917-922, 2012.

[31] M. Rodell, I. Velicogna, and J. S. Famiglietti, "Satellite-based estimates of groundwater depletion in India," Nature, vol. 460, no. 7258, pp. 999-1002, 2009.

[32] V. M. Tiwari, J. Wahr, and S. Swenson, "Dwindling groundwater resources in northern India, from satellite gravity observations," Geophysical Research Letters, vol. 36, no. 18, 2009.

[33] J. Dong, J. Wang, Y. Huang, X. Ding, J. Fu, and K. Zhou, "The review of grace data applications in terrestrial hydrology monitoring," Advances in Meteorology, vol. 24, no. 7, pp. 758767, 2014

[34] H. Shen, M. Leblanc, S. Tweed, and W. Liu, "Groundwater depletion in the Hai River Basin, China, from in situ and GRACE observations," Hydrological Sciences Journal, vol. 60, no. 4, pp. 671-687, 2015.

[35] M. Rodell, J. S. Famiglietti, J. Chen et al., "Basin scale estimates of evapotranspiration using GRACE and other observations," Geophysical Research Letters, vol. 31, no. 20, 2004.

[36] G. Ramillien, F. Frappart, A. Güntner, T. Ngo-Duc, A. Cazenave, and K. Laval, "Time variations of the regional evapotranspiration rate from Gravity Recovery and Climate Experiment (GRACE) satellite gravimetry," Water Resources Research, vol. 42, no. 10, Article ID W10403, 2006.

[37] T. H. Syed, J. S. Famiglietti, and D. P. Chambers, "GRACEbased estimates of terrestrial freshwater discharge from basin to continental scales," Journal of Hydrometeorology, vol. 10, no. 1, pp. 22-40, 2009.

[38] M. Becker, B. Meyssignac, L. Xavier, A. Cazenave, R. Alkama, and B. Decharme, "Past terrestrial water storage (1980-2008) in the Amazon Basin reconstructed from GRACE and in situ river gauging data," Hydrology \& Earth System Sciences, vol. 15, no. 2, pp. 533-546, 2011.

[39] M. Xu, B. Ye, Q. Zhao, S. Zhang, and J. Wang, "Estimation of water balance in the source region of the Yellow River based on GRACE satellite data," Journal of Arid Land, vol. 5, no. 3, pp. 384-395, 2013.

[40] L. Chevalier, B. Laignel, N. Massei et al., "Hydrological variability of major French rivers over recent decades, assessed from gauging station and GRACE observations," Hydrological Sciences Journal, vol. 59, no. 10, pp. 1844-1855, 2014.

[41] T. Zhang, R. G. Barry, K. Knowles, J. A. Heginbottom, and J. Brown, "Statistics and characteristics of permafrost and ground-ice distribution in the Northern Hemisphere," Polar Geography, vol. 31, no. 1-2, pp. 47-68, 2008.

[42] R. R. Muskett and V. E. Romanovsky, "Alaskan Permafrost groundwater storage changes derived from GRACE and ground measurements," Remote Sensing, vol. 3, no. 2, pp. 378-397, 2011.

[43] S. Vey, H. Steffen, J. Müller, and J. Boike, "Inter-annual water mass variations from GRACE in central Siberia," Journal of Geodesy, vol. 87, no. 3, pp. 287-299, 2013.

[44] M. Xu, S. Kang, Q. Zhao, and J. Li, “Terrestrial water storage changes of permafrost in the three-river source region of the Tibetan Plateau, China," Advances in Meteorology, vol. 2016, Article ID 4364738, 13 pages, 2016. 
[45] M. Zhong, J. B. Duan, H. Z. Xu, P. Peng, H. M. Yan, and Y. Z. $\mathrm{Zhu}$, "Trend of China land water storage redistribution at mediand large-spatial scales in recent five years by satellite gravity observations," Chinese Science Bulletin, vol. 54, no. 5, pp. 816821, 2009.

[46] Q. Li, Z. C. Luo, and B. Zhong, "Terrestrial water storage changes of the 2010 southwest China drought detected by GRACE temporal gravity field," Chinese Journal of Geophysics, vol. 56, no. 6, pp. 1843-1849, 2013.

[47] Y. P. Shen, S. Y. Liu, Y. J. Ding, and S. Wang, "Glacier mass balance change in tailanhe river watersheds on the south slope of the tianshan mountains and its impact on water resources," Journal of Glaciology \& Geocryology, vol. 25, no. 2, pp. 124-129, 2003.

[48] R. Zhang, P. X. Liu, K. X. Zhang, and W. X. Jia, "Analysis of spatial differences, mutation and multi-scale atributes of sunshine duration in the Qilian Mountains," Resources Science, vol. 32, no. 12, pp. 2413-2418, 2010.

[49] S. Swenson and J. Wahr, "Post-processing removal of correlated errors in GRACE data," Geophysical Research Letters, vol. 33, no. 8, Article ID L08402, 2006.

[50] S. Bettadpur, "CSR Level-2, insights into the Earth system mass variability from CSR-RL05 GRACE gravity fields," in $E G U$ General Assembly 2012; EGU2012-6409, vol. 14, Geophysical Research Abstracts, Vienna, Austria, 2012.

[51] F. W. Landerer and S. C. Swenson, "Accuracy of scaled GRACE terrestrial water storage estimates," Water Resources Research, vol. 48, no. 4, 2012.

[52] A. Paulson, S. J. Zhong, and J. Wahr, "Inference of mantle viscosity from GRACE and relative sea level data," Geophysical Journal International, vol. 171, no. 2, pp. 497-508, 2007.

[53] Y. Ding, D. Yang, B. Ye, and N. Wang, "Effects of bias correction on precipitation trend over China," Journal of Geophysical Research Atmospheres, vol. 112, no. 13, 2007.

[54] M. Xu, Y. Wang, Z. Y. Zhou, B. S. Ye, and S. H. Yi, "Discussion of methods on spatial interpolation for monthly temperature data in Yangtze River basin," Resources \& Environment in the Yangtze Basin, vol. 21, pp. 327-334, 2012.

[55] P. K. Xu and W. C. Zhang, "Inversion of terrestrial water storage changes in recent years for Qinghai-Tibetan plateau and Yarlung Zangbo River basin by GRACE," Journal of Water Resources \& Water Engineering, vol. 24, no. 1, pp. 23-29, 2013.

[56] G. F. Zhang, Z. Q. Li, W. B. Wang, W. D. Wang, H. L. Li, and B. J. Huai, "Change processes and characteristics of mass balance of the Urumqi Glacier No. 1 at the headwater of the Urumqi River, Tianshan Mountains, during 1959-2009," Journal of Glaciology \& Geocryology, vol. 34, no. 6, pp. 1301-1309, 2012.

[57] D. Farinotti, L. Longuevergne, G. Moholdt et al., "Substantial glacier mass loss in the Tien Shan over the past 50 years," Nature Geoscience, vol. 8, no. 9, pp. 716-722, 2015.

[58] K. Yoshikawa and L. D. Hinzman, "Shrinking thermokarst ponds and groundwater dynamics in discontinuous permafrost near Council, Alaska," Permafrost and Periglacial Processes, vol. 14, no. 2, pp. 151-160, 2003.

[59] K. M. Hinkel, W. R. Eisner, J. G. Bockheim, F. E. Nelson, K. M. Peterson, and X. Dai, "Spatial extent, age, and carbon stocks in drained thaw lake basins on the Barrow Peninsula, Alaska," Arctic, Antarctic, and Alpine Research, vol. 35, no. 3, pp. 291-300, 2003.

[60] K. M. Hinkel, R. C. Frohn, F. E. Nelson, W. R. Eisner, and R. A. Beck, "Morphometric and spatial analysis of thaw lakes and drained thaw lake basins in the western Arctic Coastal Plain, Alaska," Permafrost \& Periglacial Processes, vol. 16, no. 4, pp. 327-341, 2005.

[61] L. H. Cheng and Y. G. Qu, Water and Land Resources and Their Rational Development and Utilization in the Hexi Region, Science Press, Beijing, China, 1992.

[62] J. H. Yang, Z. H. Jiang, and X. Y. Liu, "Influence research on spring vegetation of Eurasia to summer drought-wetness over the northwest China," Arid Land Geography, vol. 35, no. 1, pp. $10-22,2012$.

[63] W. W. Qi, P. P. Zhang, Y. Pang, F. Zhao, and S. Zhang, “TRMMdata-based spatial and seasonal patterns of precipitation in the qinghai-tibet plateau," Scientia Geographica Sinica, vol. 33, no. 8, pp. 999-1005, 2013.

[64] D. L. Zhang, The Temporal and Spatial Variations of Water Resource Over the Tibet Plateau, Lan Zhou University, 2013.

[65] R. R. Muskett and V. E. Romanovsky, "Groundwater storage changes in arctic permafrost watersheds from GRACE and insitu measurements," Environmental Research Letters, vol. 4, no. 4, 2009.

[66] Y. P. Shen, H. C. Su, and G. Y. Wang, “The responses of glaciers and snow cover to climate change in Xinjiang(1): hydrological effect," Journal of Glaciology \& Geocryology, vol. 35, no. 3, pp. 513-527, 2013. 

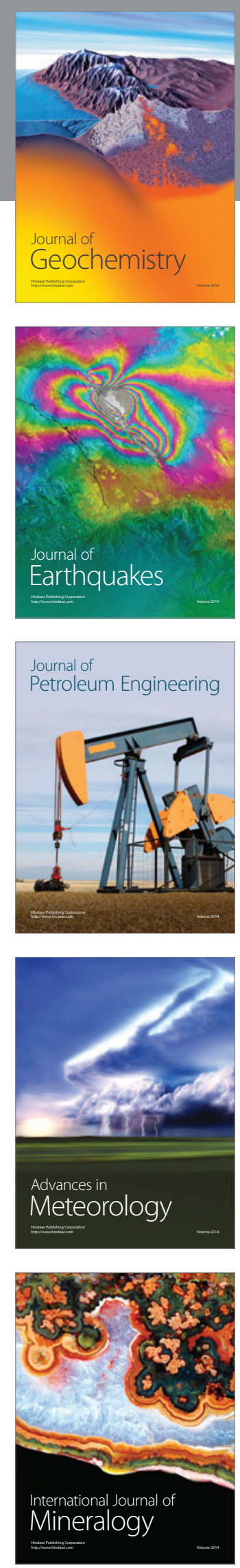
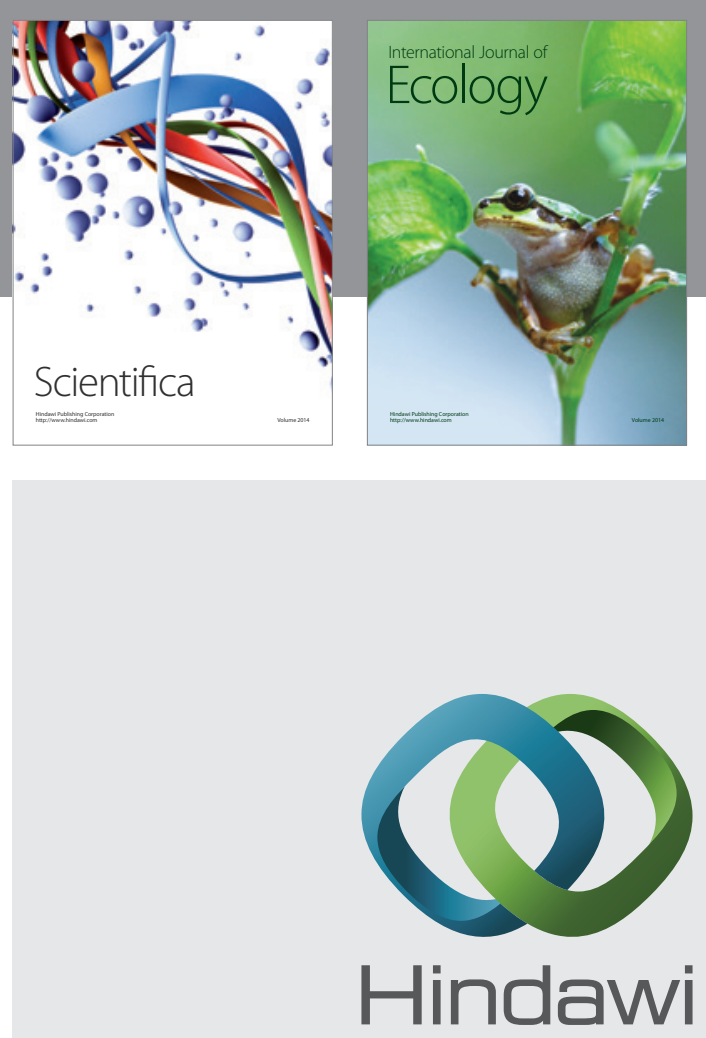

Submit your manuscripts at

https://www.hindawi.com
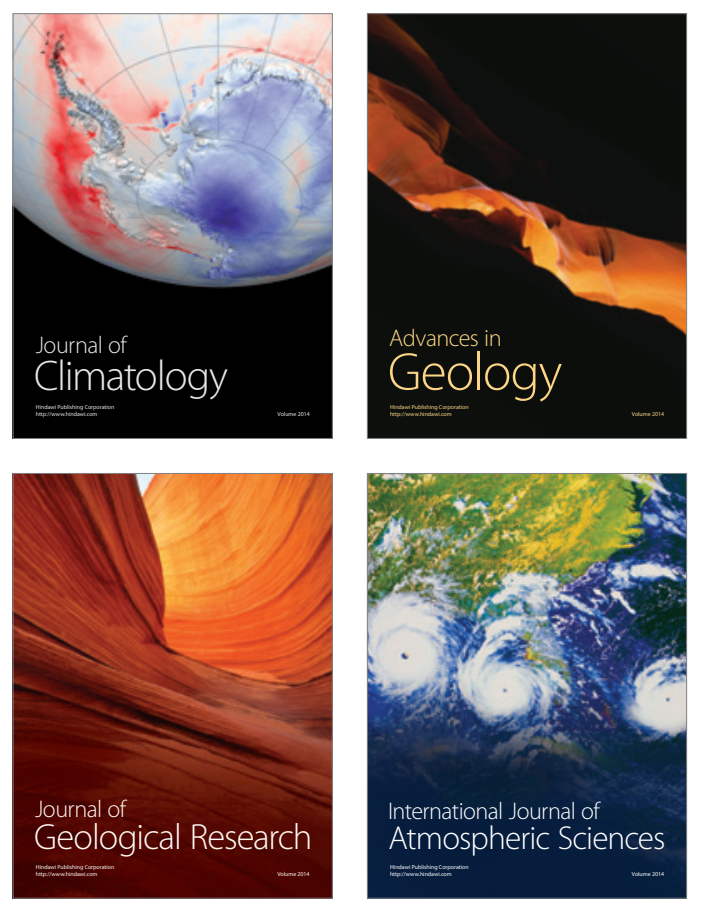

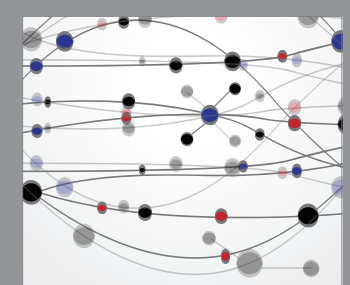

The Scientific

\section{World Journal}
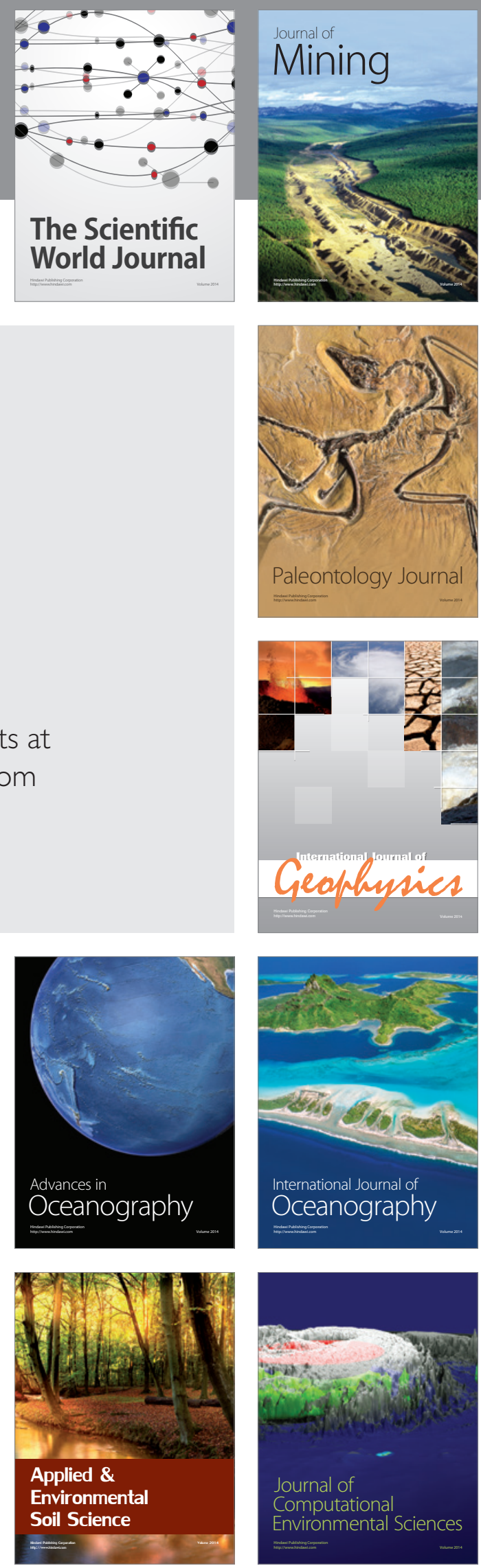